\title{
COVID-19: A Review of the Pandemic with Emphasis on the Role of Imaging
}

\begin{abstract}
Heretofore, the COVID-19 pandemic continues to expand costing not just lives but also significant impact on the global economy. More than 212 countries and territories across the globe have been affected till now, causing approximately 4,043,068 confirmed cases and 277,016 deaths, and the numbers are rising expeditiously. The common symptoms are fever, dry cough, fatigue, sputum production, shortness of breath, sore throat, and headache, but atypical symptoms affecting cardiovascular system, gastrointestinal system, and neurological manifestations are not so uncommon and have been reported. Various governing bodies such as the World Health Organization, the National Institute for Health and Care Excellence, and the Centers for Disease Control and Prevention have laid down guidelines and recommendations for the same. In this review article, we have propounded the established knowledge about the causative agent in terms of epidemiological features, the etiopathogenesis, signs and symptoms, methods used for diagnosis, and the latest insight into the treatment and prevention according to the recent published recommendations. The current guidelines and the state-of-the-art updates for various active health-care personnel; allied departments such as radiology and microbiology, and those for the community have also been discussed.
\end{abstract}

Keywords: Coronavirus, COVID-19, imaging, $n C O V$, pandemic, radiologist, SARS-CoV-2

\section{Highlights}

- Patients with COVID-19 may have normal imaging

- CT thorax may be indicated in patients with negative RT-PCR and having clinical symptoms that are in favor of COVID-19

- There is no role of chest imaging in mild disease regardless of risk factors and positive test result for COVID-19 but indicated in those showing worsening of dyspnea or hypoxemia

- CT may be reserved for patients who have had sudden clinical deterioration

- When faced with community spread, CT might serve as a tool to diagnose patients with high index of suspicion, however it may still be challenging to differentiate COVID-19 from other atypical pneumonias

- In ICU, patient's point-of-care ultrasound (POCUS) is a viable and logistically practical imaging tool.

\section{Introduction}

The epicenter of the outbreak of new novel coronavirus, now renamed as COVID-19,

\footnotetext{
This is an open access journal, and articles are distributed under the terms of the Creative Commons Attribution-NonCommercial-ShareAlike 4.0 License, which allows others to remix, tweak, and build upon the work non-commercially, as long as appropriate credit is given and the new creations are licensed under the identical terms.
}

For reprints contact: WKHLRPMedknow_reprints@wolterskluwer.com happened in Wuhan city, Hubei province, China, in December 2019. This highly contagious virus has spread rapidly across the globe with approximately 4,043,068 confirmed cases as of date May 09, 2020[1] [Figure 1]. Coronaviruses $(\mathrm{CoV})$ belong to a large family of viruses; the novel coronavirus (2019-nCoV) being a new strain which has not been previously identified in humans causes illness ranging from the common cold as a minor symptom to more severe respiratory diseases. Hitherto, the high disease burden has led to nearly 277,016 deaths worldwide, with the USA and Spain as the worst-hit countries as of May 9, 2020 [Figure 1]. Amidst the crisis, the health-care establishments and the governments are trying to cope up with the current scenario with day-to-day decisions and coming up with the new guidelines to contain the spread. We present a review article with the emphasis on the virion epidemiology, etiopathogenesis, disease spectrum, role of imaging, and also the treatment and preventive strategies according to the latest available guidelines.

\section{Epidemiology}

CoVs belong to the family of Coronaviridae and fall under the Coronaviridae subfamily

How to cite this article: Bothra M, Shera TA, Bajpai J, Mahajan A. COVID-19: A review of the pandemic with emphasis on the role of imaging. Indian J Med Paediatr Oncol 2020;41:640-51.

\section{Mohnish Bothra', Tahleel Altaf Shera ${ }^{2}$, Jyoti Bajpai', Abhishek Mahajan ${ }^{1}$}

${ }^{1}$ Department of Radiodiagnosis, Tata Memorial Hospital,

Mumbai, Maharashtra, India, ${ }^{2}$ Department of Radiodiagnosis, Sher I Kashmir Institute of Medical Sciences, Srinagar, Jammu and Kashmir, India, ${ }^{3}$ Department of Medical Oncology, Tata Memorial Hospital, Mumbai,

Maharashtra, India

Submitted: 10-May-2020

Revised: 09-Jun-2020

Accepted: 25-Jun-2020

Published: 29-Oct-2020

Address for correspondence: Prof. Abhishek Mahajan, Department of Radiodiagnosis, Tata Memorial Hospital, Mumbai - 400 012,

Maharashtra, India.

E-mail:drabhishek.mahajan@ yahoo.in

Access this article online Website: www.ijmpo.org

DOI: 10.4103/ijmpo.ijmpo_223_20 Quick Response Code:

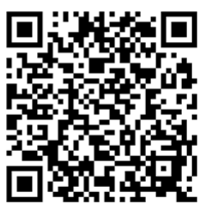




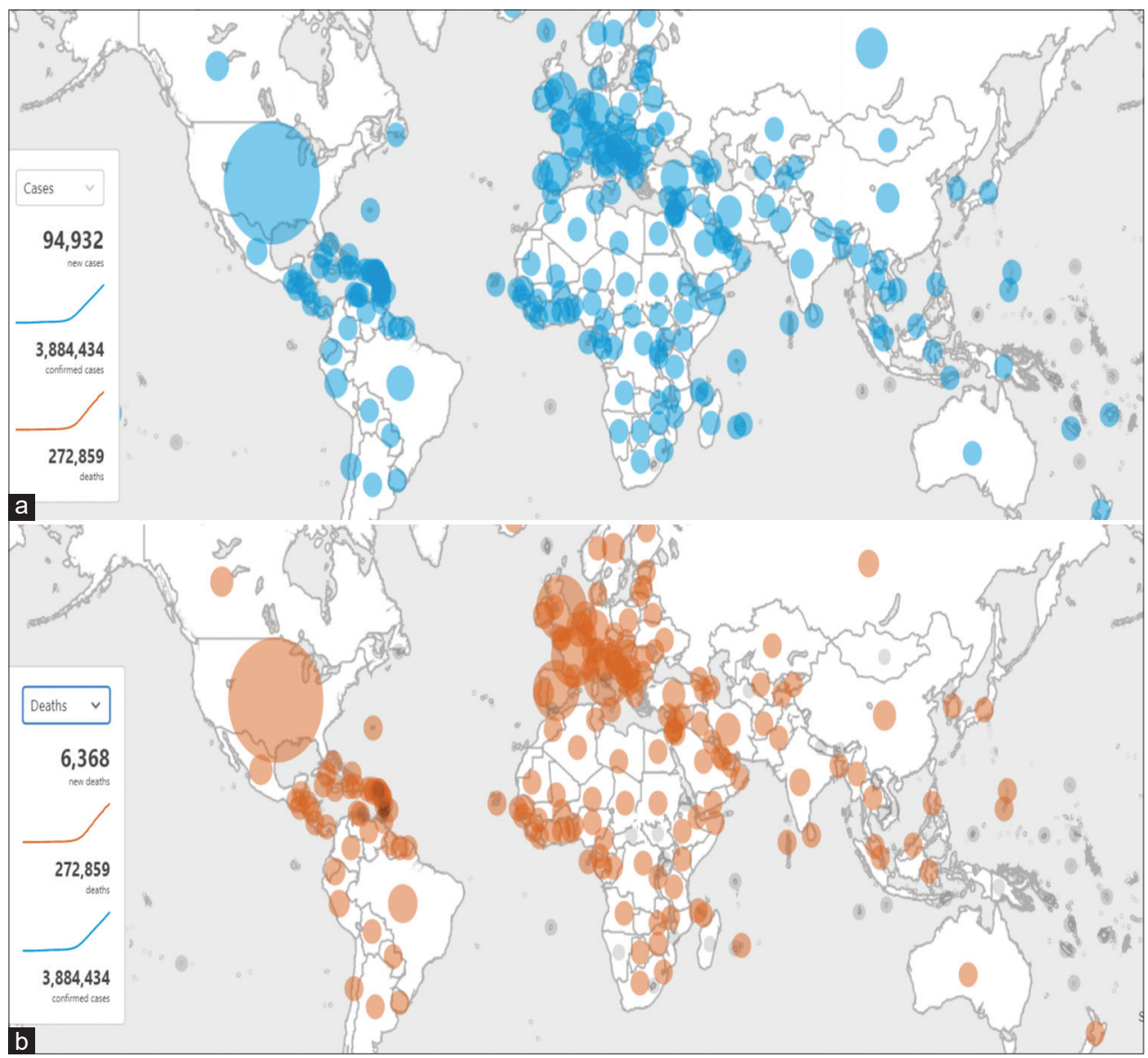

Figure 1: ( $a$ and b) COVID-19 cases and deaths worldwide by the World Health Organization - available at https://who.sprinklr.com/accessed April 22, 2020

which is a single-stranded (positive sense) RNA associated with a nucleoprotein within a capsid composed of matrix protein. ${ }^{[2]}$ The envelope bears club or crown-shaped glycoprotein projections. According to Lauer SA et al. the median incubation period was estimated to be in the range of 5.1-15.6 days with an assumption that the 99th percentile of the cases will develop symptoms within 14 days of acquiring the infection. ${ }^{[3]}$ There is an association of age and immunity status of the patient as evident by shorter incubation period seen in patients $<70$ years of age than in those $>70$ years. ${ }^{[4]}$ The positive cases $(55.1 \%)$ in the age range of 15-49 years clearly outnumbered the other groups, which were seen as $28.9 \%$ in $50-64$ years while $15.1 \%$ in age 65 years and above. ${ }^{[5]}$ The World Health Organization (WHO) declared COVID-19 as a public health emergency of international concern. ${ }^{[6]}$

\section{Mode of Spread}

The predominant mode of spread is via airborne route with human-to-human infection between close contacts ( $<6$ feet) and as a droplet infection when an infected person coughs or sneezes; the infected droplets are either inhaled by the healthy individuals in the vicinity and or land up in the mouth or nose [Figure 2]. The other mode of spread to a healthy individual is via fomites which are infected or contaminated objects having viable virus on their surface. ${ }^{[7]}$ The intermediate source of origin and transfer to humans is unknown; however, the possibility of it being a zoonotic disease (via infected bats) is likely. ${ }^{[8]}$

\section{Etiopathogenesis}

The primary target of the virion is the epithelial cells of the lung with affinity of the receptor-binding domain spike on the envelope of the virus particle to the angiotensin-converting enzyme 2 receptor in the host. ${ }^{[9,10]}$ After its entry into the host cell, the genome is uncoated and is followed by transcription and translation; the virus replicates in the cells of ciliated epithelium, causing damage to the host cell, and incites inflammation. ${ }^{[1]}$

\section{High-Risk Population}

This includes the elderly typically 65 years and older; those living in long-term facility and nursing home; people with underlying medical conditions, for example, chronic lung disease, cardiac disease, liver disease, chronic kidney disease, diabetes, and immunosuppression secondary to HIV/AIDS, long-term steroid use, bone marrow and organ transplantation, and cancer patients. ${ }^{[12]}$ Cancer patients undergoing treatment with chemotherapy and radiotherapy, 
those suffering from hematological neoplasm, or those who have received bone marrow transplant or stem cell transplant as a part of the treatment $<6$ months' duration or are put on drugs altering the immune systems such as PARP inhibitors or protein kinase inhibitors are the most susceptible among the lot. ${ }^{[13]}$

\section{Signs and Symptoms}

The signs and symptoms of COVID-19 infection are highly variable and are nonspecific ranging from asymptomatic carrier to typical respiratory symptoms and/or rarely systemic manifestations pertaining to gastrointestinal and cardiovascular systems. ${ }^{[5,14-17]}$ In the given current scenario, the symptoms in the pediatric population are milder as compared to the adults. ${ }^{[18,19]}$ The most common symptoms are fever $(87.9 \%)$, followed by dry cough $(67.7 \%)$, fatigue $(38.1 \%)$, sputum production $(33.4 \%)$,

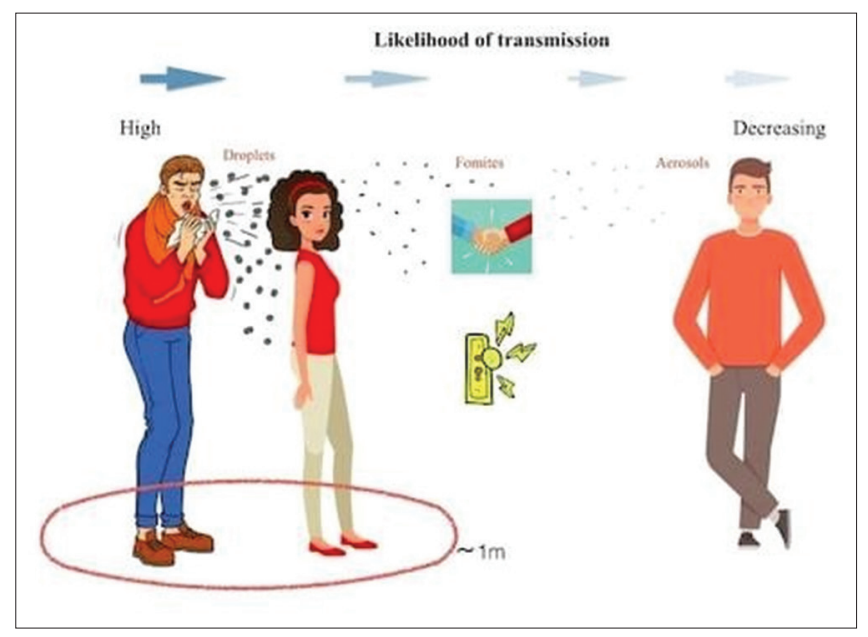

Figure 2: Depiction of how droplets can travel in air and spread infection shortness of breath $(18.6 \%)$, sore throat $(13.9 \%)$, headache $(13.6 \%)$, myalgia/arthralgia $(14.8 \%)$, chills (11.4\%), nausea and vomiting (5.0\%), nasal congestion $(4.8 \%)$, diarrhea $(3.7 \%)$, hemoptysis $(0.9 \%)$, conjunctival congestion $(0.8 \%)$, and acute respiratory distress syndrome (ARDS) (3\%). ${ }^{[5]}$ Various societies across the globe are coming up with guidelines and recommendations in various subspecialties; one such example is British Thoracic Society which has published the guidelines for the respiratory community - https:// www.brit-thoracic.org.uk/quality-improvement/guidelines/. The clinical classification of cases given by the Chinese clinical guidance for COVID-19 pneumonia diagnosis and treatment $\left(7^{\text {th }}\right.$ ed.ition) is summarized in Table 1.

\section{Diagnosis}

The state-of-the-art test for COVID-19 is real-time reverse transcriptase-polymerase chain reaction (RT-PCR). The specimen for endemic forms of human $\mathrm{CoV}$ infections has been isolated from various areas, namely, nasal swab or nasopharyngeal (NP), throat, sputum, and bronchoalveolar lavage (BAL). The current Centers for Disease Control and Prevention (CDC) recommend collection of specimens from upper respiratory tract, preferably NP swab. ${ }^{[20]}$ Laboratories are required to maintain the adequate temperature chain to store the specimen, i.e., maintaining refrigerated temperature for up to $72 \mathrm{~h}$ or frozen at $-70^{\circ}$ or even below it. ${ }^{[18]}$ Regarding the biosafety guidelines, the $\mathrm{CDC}$ has recommended the BSL 2 laboratories to deal with regulation of the specimen. ${ }^{[21]}$ Early infections may be missed and repeat swabs may be taken for highly suspicious cases later in the course of illness. Serum and rectal specimens alternatively can be used. ${ }^{[22]}$

Table 1: Clinical classification of cases given by Chinese clinical guidance for COVID-19 pneumonia diagnosis and treatment $\left(7^{\text {th }}\right.$ edition)

\begin{tabular}{ll}
\hline Grading & Clinical criteria \\
\hline Mild & Mild clinical symptoms and no sign of pneumonia on chest imaging \\
Moderate & Fever and respiratory symptoms present along with radiological evidence of pneumonia
\end{tabular}

Severe

Adults (any of the following) Shortness of breath (RR $\geq 30 / \mathrm{min}$ )

Oxygen saturation $\leq 93 \%$ at rest

Alveolar oxygen partial pressure/fraction of inspiration oxygen (Pa oxygen/Fi oxygen $\leq 300 \mathrm{mmHg}$ and patients showing progression of evidence of pneumonia $>50 \%$ on imaging within $24-48 \mathrm{~h}$

Children (any criteria) Shortness of breath $(<2$ months of age $-\mathrm{RR} \geq 60$ breaths $/ \mathrm{min}, 2-12$ months of age $-\mathrm{RR} \geq 40$ breaths/min, 5 years old $-\mathrm{RR} \geq 30$ breaths/min excluding the effects of fever and crying

Oxygen saturation in resting state $\leq 92 \%$

Assisted breathing (groaning, wing flaps, tri-retraction sign), cyanosis, intermittent apnea

Lethargy and convulsion

Refuse to feed or having signs of dehydration

Critically severe (any of Respiratory failure requiring mechanical ventilation

following)

Shock

Patients combined with other failures needed ICU monitoring and treatment

Adapted from: http://kjfy.meetingchina.org/msite/news/show/cn/3337.html]. ICU - Intensive care unit; RR - Respiratory rate 


\begin{tabular}{lc}
\hline & Table 2: COVID-19 pneumonia imaging classification \\
\hline Features & Imaging pattern and inference \\
\hline Typical appearance & Imaging features are consistent with those of COVID-19, however similar imaging appearance can also be seen \\
in other entities, hence detailed history and medical records should be correlated \\
Bilateral, peripheral, subpleural involvement, GGO \pm consolidation or crazy paving pattern secondary to \\
interlobular septal thickening \\
Other morphological patterns of GGO such as multifocal and round-shaped \pm crazy paving and consolidation \\
Findings favoring organizing pneumonia, for example, reverse halo sign \\
Overall findings can represent possible COVID-19 infection \\
Andeterminate features \\
Presence of typical features and \\
GGOs \pm consolidation, suggesting nonspecific pattern of distribution \\
Nonperipheral and nonround morphology of few very small GGOs \\
Alternate diagnosis should be considered. The chances of it being COVID-19 are less likely \\
Absence of typical or indeterminate features and \\
Presence of \\
Single lobar or segmental consolidation without GGO \\
Tree in bud pattern representing discrete small centrilobular nodules \\
Cavitary changes in lung parenchyma \\
Crazy paving with pleural effusion \\
No evidence of pneumonia in the current study. CT chest may be normal in early stages of disease \\
No imaging features to suggest pneumonia in the current study \\
Negative for
\end{tabular}

CT - Computed tomography; GGO - Ground-glass opacities

\section{Laboratory diagnosis}

It mainly consists of a battery of routine blood investigations with few generalized observations such as lymphopenia, which tends to be a poor prognostic indicator. ${ }^{[23]}$ There is a rise in the acute-phase reactants such as C-reactive protein (CRP), lactate dehydrogenase (LDH), prothrombin time (PT), D-Dimer, and liver enzymes. Later, in the disease, there may be rise in the organ-specific proteins and markers, which heralds the poor prognosis of the individual. ${ }^{[23]}$

\section{Role of Radiology and Imaging}

The role of diagnostic radiology as a tool in the current scenario is being constantly updated with various publications, review articles, and their immediate incorporation into various guidelines given by international and national health governing bodies. The role of screening computed tomography (CT) for COVID-19 has been called off by many radiological societies. ${ }^{[24]}$ Lately, plain radiography and CTs are used as a part of diagnostic armamentarium with acceptable levels of detection and follow-up of cases under specific regulations and indications. Chest radiography despite being less sensitive than CT continues to be used the first radiological investigation across the globe. ${ }^{[25]}$ In conjunction to it, the Indian chest societies such as IRIA ICRI chest subspecialty group have also come up with the same. To minimize the risk of contamination of the radiology department and the radiology personnel, special emphasis is laid on the use of portable radiography using dedicated machinery with defined protocols as directed by various health-care providers across nations and the world. ${ }^{[26]}$
The radiographic evidence of abnormality is most obvious at 10-12 days after development of symptoms, whereas in the early or mild course of the disease, no abnormality is detected. ${ }^{[25]}$ The sensitivity and specificity of chest radiography is low as compared to that of the CT. The predominant abnormality on radiographs is patchy areas of consolidation (28.1\%) followed by ground-glass opacities (GGOs) (20.1\%) and rarely interstitial abnormalities (4.4\%). These changes were more frequently present in bilateral distribution as seen in a study conducted by Guan et al. ${ }^{[5]}$ Lately, many publications have come up describing the imaging in COVID-19, emphasizing on CT features. ${ }^{[27-31]}$ These studies were able to decipher the common patterns of lung affection on CT such as GGOs, frequently bilateral and multilobar and infrequently as mass like or nodular pattern of opacities. ${ }^{[31]}$ The classic CT depicter for COVID-19 is diffuse involvement of lungs bilaterally with GGOs rendering crazy paving appearance with or without consolidation predominantly in peripheral and posterior aspect. ${ }^{[27-32]}$ Lymphadenopathy, pleural effusions, multiple tiny pulmonary nodules, tree in bud pattern, and cavitation have been rarely described in the spectrum as atypical findings and may represent superadded infections. ${ }^{[33]}$ A normal CT chest may be expected early in the course of disease. ${ }^{[34-36]}$ The sensitivity and specificity of CT varies in the range of $60 \%-98 \%$ and $25 \%-53 \%$, respectively. ${ }^{[37-40]}$ Table 2 - summarises the COVID-19 pneumonia imaging classification.

Recently, there have been recommendations regarding the reporting language for COVID-19 to even out the discrepancy of findings on imaging and maintain 
homogeneity among the fraternity. The proposed reporting language with the CT findings are adapted from the Society of Thoracic Radiology, the American College of Radiology, and RSNA. ${ }^{[2]}$ Figure $3 a$ and $b$ shows the CT image of a confirmed case of COVID-19. COVID mimics - few examples of mimics of the disease owing to the varied patterns on CT imaging are shown in Figures 4 and $5 \mathrm{a}-\mathrm{d}$.

\section{Indications of Imaging}

The Fleischner society has described the role of imaging and its use in the given setting of the pandemic on the basis of various clinical criteria and their features, as given in Table 3. ${ }^{[41]}$

\section{Recommendation}

1. Mild disease: No role of chest imaging in mild disease regardless of risk factors and positive test result for COVID-19 but indicated in those showing worsening of dyspnea or hypoxemia

2. Moderate-to-severe disease: Imaging in patients with positive COVID-19 status is recommended serving as a baseline study, to identify those with underlying cardiovascular disease for risk assessment and assess

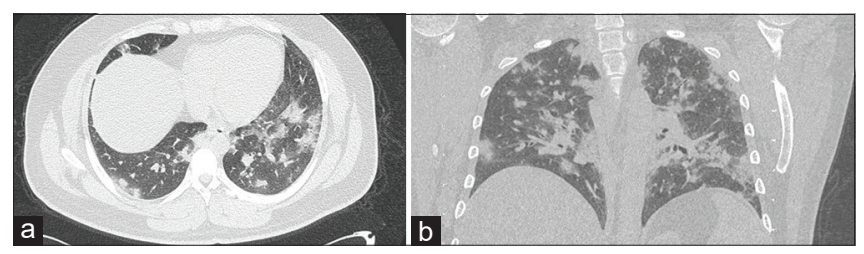

Figure 3: (a and b) A 45-year-old male patient had a history of contact with a COVID-19-positive family member who presented to the COVID clinic with a history of cough and fever of 3 days' duration. The patient had sudden clinical deterioration and breathlessness; a computed tomography thorax was advised. The findings on computed tomography thorax axial and coronal images ( $a$ and $b$ ) revealed multifocal patchy areas of round to ill-defined consolidation predominantly in the posterior and basal segments of the lung with surrounding ground-glass opacities. Reverse transcriptase-polymerase chain reaction tested positive for COVID-19 disease progression and superadded abnormalities and infections.

Other subsets of patients who are either not tested or have a negative test should undergo imaging as a part of routine care and for evaluation of the underlying pathology. If imaging features are suspicious of COVID-19 infection, these cases should be dealt further according to risk factors and lab test availability including repeat tests for COVID-19.

COVID-RADS is another such example and can be used for the structured reporting of the cases in clinical trials and can be accessed at covid19action-radiology.github.io.

The lack of dedicated CT units for the suspected patients or cases in a hospital setting and effortful sterilization and low specificity has led to the lack of endorsement in developing countries such as India. ${ }^{[42]}$ The role of ultrasonography (USG) as point of care ultrasound (POCUS) is surging as a tool because of ease of portability and sterilisation techniques, and also, it can be used as dedicated unit in isolation and critical care wards. ${ }^{[33-45]}$ It has been reinforced by recent studies in China in critical care settings. ${ }^{[46]}$ Its role is being assessed in triage and risk stratification and detection of complications such as pleural effusions. The imaging findings comprise multiple B lines and waterfall sign secondary to thickening of the interlobular septa in subpleural location, areas of focal or diffuse consolidation with air sonograms, and irregular pleural thickening with or without pleural effusion with reduced blood supply on Doppler. ${ }^{[47]}$ The preparation of ultrasound transducer consists of cleaning and disinfection as recommended by the International Society of Ultrasound in Obstetrics and Gynecology with the use of low- or high-level disinfectants compiled and available on https:/obgyn.onlinelibrary.wiley.com/doi/ epdf/10.1002/uog. 22027, and also the methods and compatibility with the equipment have been already provided by various vendors. The technique of performing

\begin{tabular}{|c|c|}
\hline Criteria & Features \\
\hline \multicolumn{2}{|l|}{ Severity of disease } \\
\hline \multirow[t]{3}{*}{ Mild } & Absence of hypoxemia \\
\hline & No or mild dyspnea \\
\hline & Suggestive of absence of significant pulmonary damage \\
\hline \multirow[t]{3}{*}{ Moderate to severe } & Presence of hypoxemia \\
\hline & Moderate to severe dyspnea \\
\hline & Suggestive of presence of significant pulmonary damage \\
\hline \multicolumn{2}{|l|}{ Risk factors } \\
\hline Present & $\begin{array}{l}\text { Clinical assessment in patients with age }>65 \text { years and presence of comorbidities such as diabetes mellitus, } \\
\text { chronic respiratory disease, cardiovascular disease, and compromised immune status }\end{array}$ \\
\hline Absent & $\begin{array}{l}\text { No positive risk factors and features suggesting progression of disease from mild to moderate/severe, worsening } \\
\text { of hypoxemia }\end{array}$ \\
\hline \multicolumn{2}{|l|}{ Pretest probability } \\
\hline Low, medium, and high & Depending on mode of transmission, i.e., sporadic, clustered, and community transmission \\
\hline
\end{tabular}




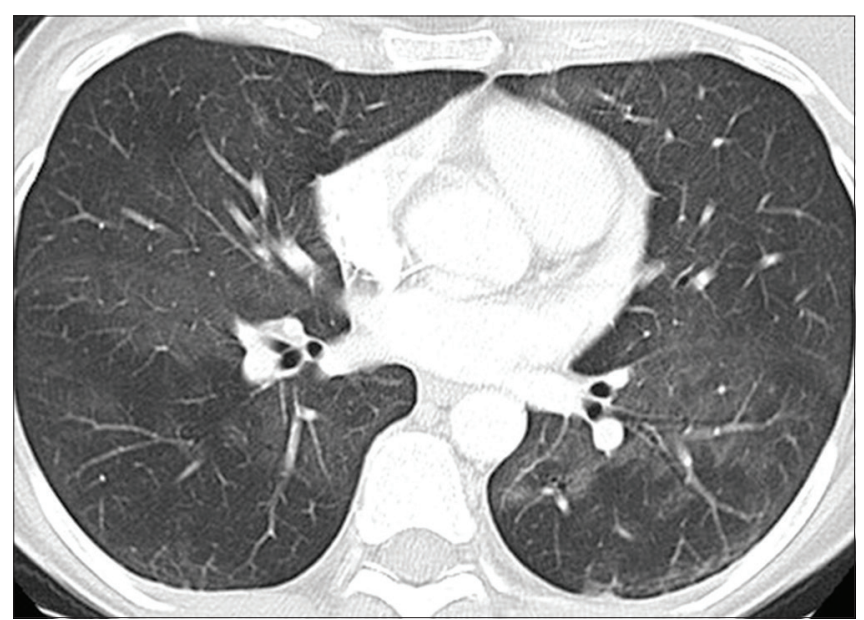

Figure 4: A 45-year-old female patient with carcinoma breast developed fever and breathlessness after infusion of paclitaxel therapy. Computed tomography axial image was suggestive of faint bilateral ground-glass opacities predominantly in the bilateral lung bases. On cessation of therapy, there was significant improvement in the ground-glass opacities

ultrasound of chest for the patients has been stipulated by Soldati, et al.,,$^{[48]}$ which recommends the use of convex or linear transducers according to the individual patients with low mechanical index $<0.7$ and suggests to avoid the usage of tissue harmonic imaging, Doppler imaging, compound, and contrast enhancing methods. For those who are not able to maintain a sitting position or are on invasive method of ventilation, the checklist consists of a minimum of eight areas which would amount to the total scan duration of approximately 2-3 min. The region of interest is anteriorly in the mid clavicular line above and below the internipple line, laterally midaxillary line both above and below the internipple line, and posteriorly the base of the lung on both sides. ${ }^{[49]}$ Similarly, for stable patients, they have proposed 14 sites to be examined along the anterior, laterals and posterior aspects of the chest wall. ${ }^{[48]}$

\section{Management}

\section{Treatment and prevention}

To this date, no specific antiviral therapy or vaccine is approved by the CDC, the WHO, and the U.S. Food and Drug Administration for the treatment of COVID-19 infection, thus the management of cases is primarily symptomatic and with use of empirical drugs to combat life-threatening conditions secondary to disease progression and superadded infections. ${ }^{[49-51]}$ The treatment strategy emphasizes on the administration of oxygen and respiratory support through various available methods. What is expected out of the entire remainder of healthy individuals in these trying times is to pay stern attention to meticulous hand hygiene, donning face mask, cough etiquettes, avoid gathering and crowded environments, and self-isolation. ${ }^{[2]}$ All the patients should be screened for symptoms at the entry point of the health care facility as a part of infection prevention and control. ${ }^{[52]}$ The health-care facilities shall

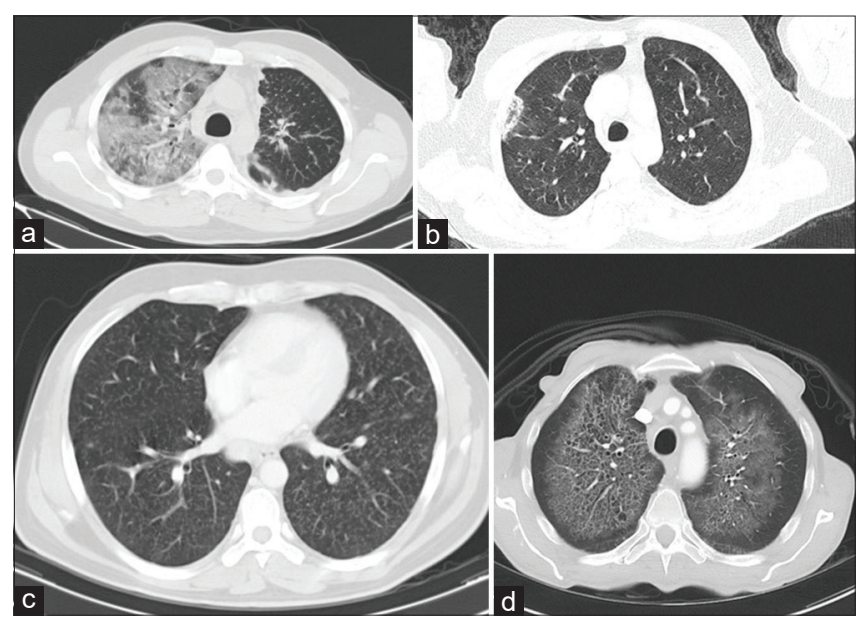

Figure 5: (a) An elderly patient presented with haemoptysis and breathlessness. Axial computed tomography lung window demonstrates patchy areas of ground-glass opacities with interlobular and intralobular septal thickening - giving "crazy paving pattern" in the right upper lobe and also in the bilateral lower lobes. Imaging findings were consistent with diffuse pulmonary haemorrhage. (b) Patient presented to the casualty with acute-onset of chest pain and cough. Axial computed tomography image lung window demonstrates a patch of consolidation in the subpleural location with central ground-glass opacities - "atoll sign" (reverse halo sign) in the right upper lobe was consistent with cryptogenic organizing pneumonia. Significant resolution was seen with corticosteroid treatment. (c) Selected axial computed tomography image lung window shows diffuse randomly distributed tiny parenchymal nodules "miliary pattern" in this elderly female patient on chemotherapy presenting with a new onset of cough, breathlessness, and fever since a month. Overall findings are in favour of infective etiology - miliary tuberculosis. Sputum was positive for acid-fast bacilli. The patient is on ATT and follow- up (d) Selected axial sections of CT chest lung window with bilateral perihilar ground glass opacities multiple pulmonary cysts with relative peripheral and subpleural sparing. No evidence of pleural effusion or mediastinal lymphadenopathy. Overall findings were in favour of pneumocystis jiroveci pneumonia which is a common opportunistic pathogen in immunocompromised individuals. The patient presented with sudden loss of consciousness and breathlessness and workup revealed HIV positive status with low CD4 counts $28 \mathrm{cells} / \mathrm{mm}^{3}$

follow all the standard precautions, for example, hand hygiene, personal protective equipment (PPE), safe waste management, and cleaning the equipment and environment. The standard operating procedure to be followed in the radiology department by staff and technologists and sanitisation of the CT facility is given in Table 4. Milder form of disease does not require any intervention at the health-care facility, but the strict need of isolation and standard precautions to contain the spread are taken care of. Severe respiratory failure should be identified and addressed with supplemental oxygenation with intubation and mechanical ventilation as required to maintain the blood oxygen saturation level. The intricate details of the management pertaining to the drug dosage and ventilator support settings and critical care, etc., are beyond the scope of this review article.

\section{Drug trials}

The use of hydroxychloroquine for the high-risk population has been recommended by the National task force for COVID-19 constituted by the Indian Council of Medical Research. The high-risk population includes those 
Table 4: Standard operating procedure and sanitization of computed tomography facility

Standard operating procedure for Compulsory use of N95 face masks by staff and the patient entering the department

the radiology staff members and technologists

Sanitization of CT room

Prerequisites

Steps

Hand disinfection by alcohol-based sanitizer for all those entering the radiology department

All requisitions except trauma patients should be approved by radiology faculty on duty

Patients posted for imaging of the abdomen and lower chest till carina should be included and if

there are any suspicious features for COVID-19 on imaging, then consider the patient as positive, CT setup should be shut down until proper disinfection done and the entire staff on duty should be home quarantined if the swab test comes positive for the given patient

Steps of disinfection should be displayed in the room

Interventional procedures - dedicated units should be used with the use of PPE for positive patients if any case has to be done in an emergency

Three small buckets and three big buckets with water, detergent water, and freshly prepared bleach or $1 \%$ sodium hypochlorite solution

Cleaning the machine with mop and detergent water, dip in water, after wringing excess water, cleaning with $1 \%$ hypochlorite solution, wring excess fluid, and wipe down again

Similar steps need to be followed for floor cleaning using large buckets and thereafter fumigation of room with $20 \%$ baccishield for $30 \mathrm{~min}$, which should remain closed for the next $45 \mathrm{~min}$

Wet cleaning of the floor once and allowing it to dry for the next 10 min after which the room can be used again

$\mathrm{CT}$ - Computed tomography; PPE - Personal protective equipment

health-care workers engaged in the treatment of suspected or confirmed cases of the disease and the household contacts of the laboratory-confirmed cases. ${ }^{[53]}$ However, both chloroquine and hydroxychloroquine have shown activity against SARS-CoV-2 in vitro models and have immunomodulating properties, but there is limited data to suggest the potential benefit. ${ }^{[54-59]}$ Protease inhibitors such as lopinavir and ritonavir have recently failed to confirm the potential benefits in a study. ${ }^{[60]}$

Remdesivir, a nucleotide analog, is being tested under several large clinical trials and has limited availability, however in the ongoing trials, it has proven to reduce the time to recovery against the placebo group. ${ }^{[61]}$ Tocilizumab as an immunomodulating agent is being used in some acceptable protocols, but the data fall short of proving it as an adjunct therapy. ${ }^{[62]}$ COVID-19 convalescent plasma is also being explored as a potential treatment. $^{[63]}$ Except for refractory shock and severe respiratory distress syndrome, the use of corticosteroids is not recommended. ${ }^{[60,64,65]}$ The use of nonsteroidal anti-inflammatory drugs has been doubted to cause clinical worsening; there is lack of clinical data to support or refute, but antipyretics, for example, acetaminophen, are recommended for fever. ${ }^{[60,66]}$ Azithromycin has been used in conjunction with hydroxychloroquine and benefit has been suggested in preclinical studies. ${ }^{[67]}$

\section{Cancer and COVID}

The morbidity and mortality from COVID is higher in cancer patients $(6 \%-20 \%)$ than in the general population $(2 \%-3 \%) \cdot{ }^{[68]}$ There is possible delay in the treatment of such cancer patients in this crisis owing to the restricted movement due to risk of acquiring infection and also modification in the treatment protocols as per the availability and feasibility which is a cause of major cancer and fear amongst these subset of patients. ${ }^{[69,70]}$ The treating oncologists are also concerned as they are working in potentially infectious surroundings with suboptimal PPE, which may lead to life-threatening situations. ${ }^{[71]}$ Triaging of patients should be done in a multidisciplinary team with appropriate documentation to avoid or handle any future medicolegal dispute. ${ }^{[72]}$

Certain principles should be followed to minimize the risk to patients and caregivers

Conscious de-intensification of therapies should be practiced including minimization of intensive systemic therapy protocols with higher risk of complications; prolongation of therapy intervals; avoidance of intravenous route; and preference for oral or subcutaneous route for all the therapies including for ancillary care. Similarly, triaging for surgery considering the risk-benefit ratio stringently needs to be followed. For example, simple surface surgeries such as the breast and the thyroid may be considered with relatively low risk, however, elective aerosol-generating procedures wherein high contamination risk exists should be minimized. For radiation, use of altered fractionation schedules such as hypofractionated UK-FAST and FAST FORWARD regimen of 5 weekly and daily fractions used for cancer such as breast can save machine time and should be considered. Similarly, one may consider using altered fractionation instead of using radiosensitizing concurrent chemotherapy depending on the scenario.

\section{Preventive measures}

Simple measures including regular washing of hands with soap and water; usage of alcohol-based sanitizers; avoiding touching eyes, nose, and mouth; maintaining 
social distancing; following self-isolation; and maintaining at least 1-m distance have been recommended by the CDC [Figure 6] and use of proper fitting N95 face mask. The method of donning and doffing of the face mask and personnel protective equipment has been recommended by the CDC. ${ }^{[73]}$ NIOSH-approved N95 respirators filter out at least $95 \%$ of tiny $(0.3-\mu$ size $)$ particles that are capable of filtering out all types of particles, including bacteria and viruses. The Government of India ordered lockdown for a period of 21 days on March 24, 2020, as a preventive measure to control the pandemic. ${ }^{[74]}$ The splendid efforts by the Government of India and many other countries, international bodies of concern, and health-care delivery system of the country together with befitting and awake positive acceptance by the individuals of the community in these trying times is the doorway to control the spread of COVID-19 infection and save lives.

\section{Conclusion}

The rapidly spreading COVID-19 pandemic has emerged as a critical challenge to the community and the health-care individuals, placing their lives in jeopardy. The infection continues to spread and various measures are being taken for its containment including rigorous government decisions and emphasis of social distancing, hand sanitization, cough
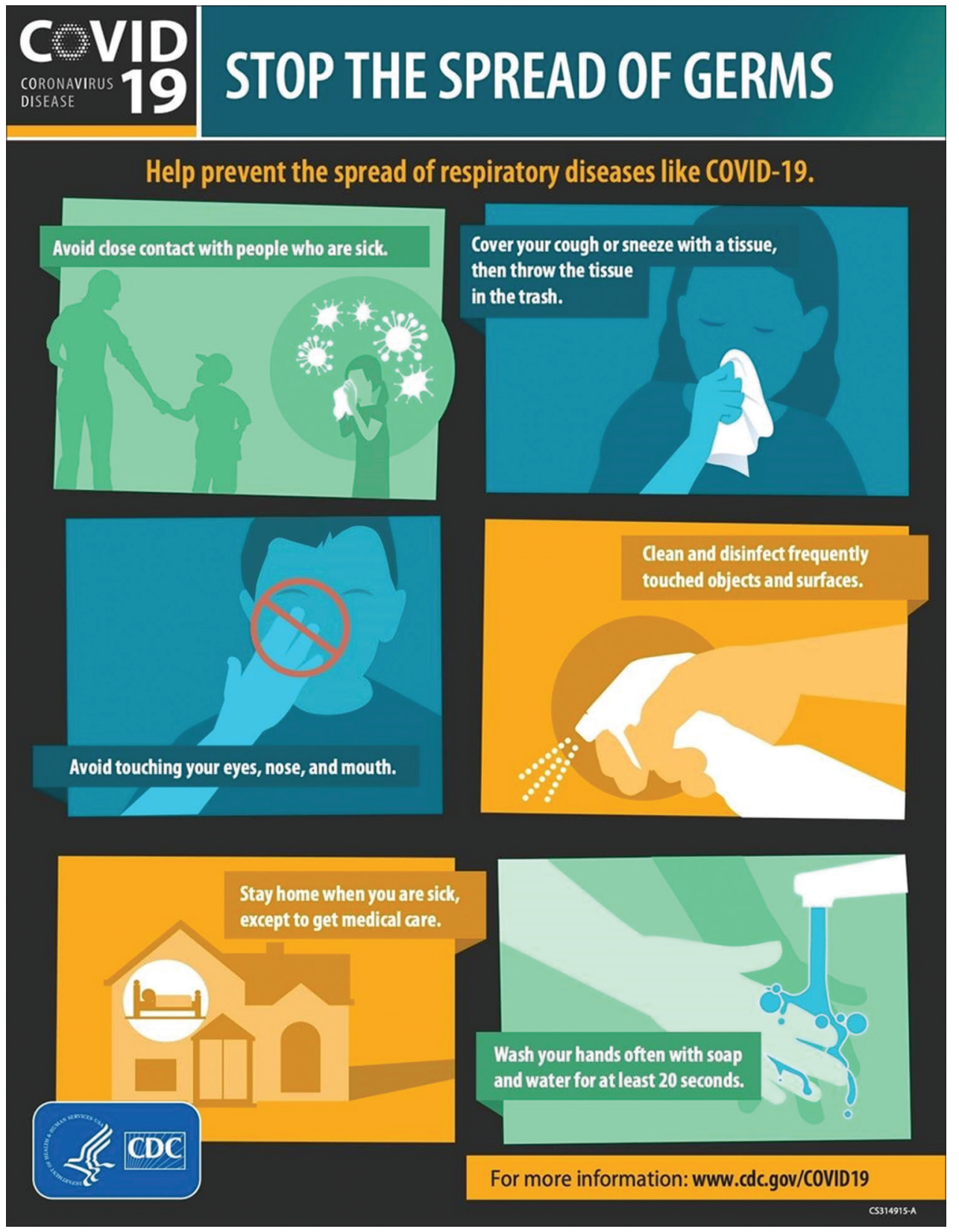

Figure 6: Tips for preventing the spread of germs, according to the Centers for Disease Control and Prevention - source: https://www.cdc.gov/ coronavirus/2019-ncov/downloads/stop-the-spread-of-germs.pdf 


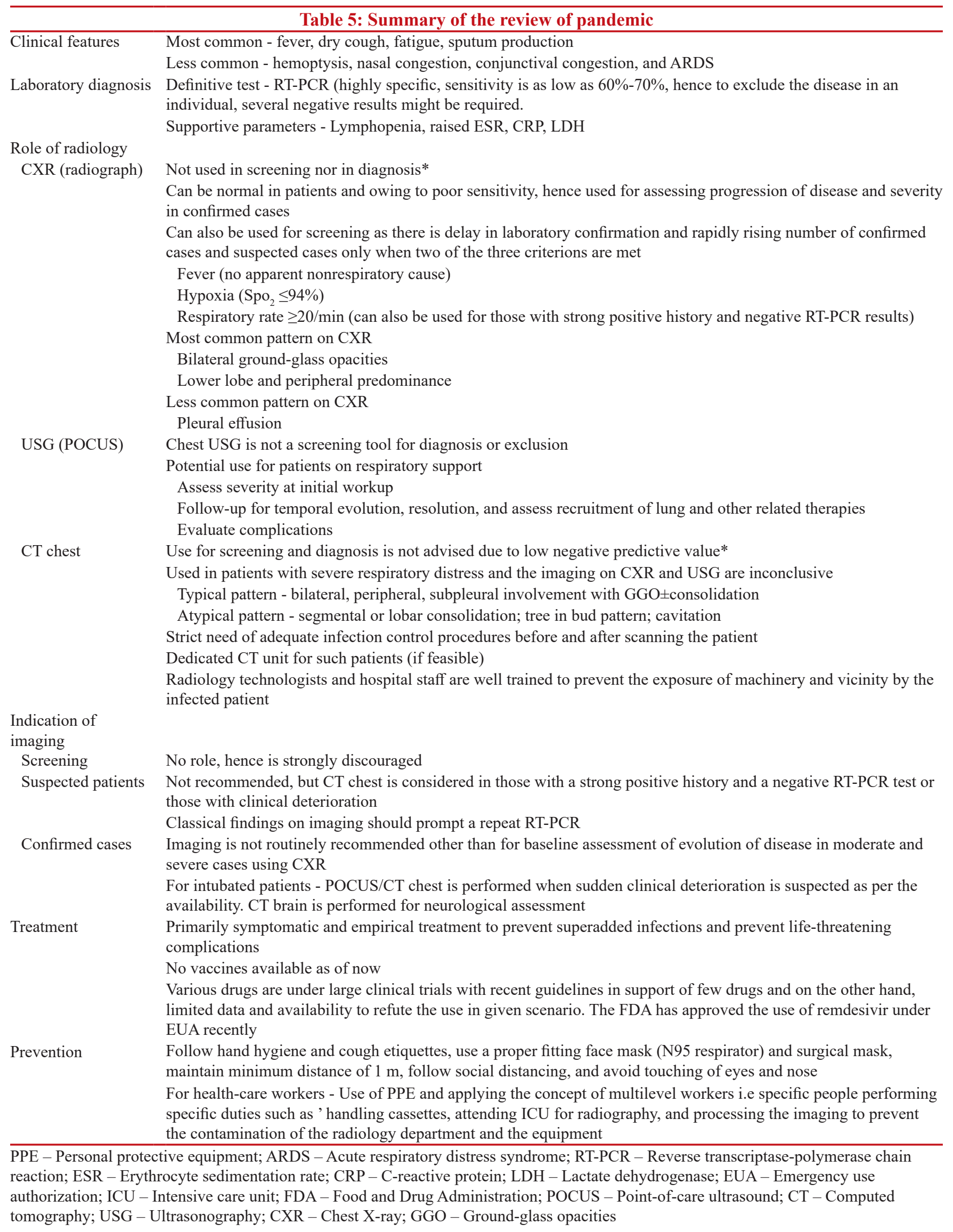


etiquettes, and use of masks to bring down its impact in terms of lives lost and rate of spread of infection. The only available laboratory test is RT-PCR which is variable through the course of illness; other supportive laboratory parameters are lymphopenia, raised erythrocyte sedimentation rate, CRP, LDH, etc., The crucial yet elusive role of imaging has been evolving in parallel with the knowledge of the disease. A summary of the review of the pandemic is given in Table 5 .

\section{Declaration of patient consent}

The authors certify that they have obtained all appropriate patient consent forms. In the form the patient(s) has/have given his/her/their consent for his/her/their images and other clinical information to be reported in the journal. The patients understand that their names and initials will not be published and due efforts will be made to conceal their identity, but anonymity cannot be guaranteed.

\section{Acknowledgment}

The authors would like to thank Dr. Rajat Agrawal, Junior Resident, Department of Radiodiagnosis, Tata Memorial Hospital, Mumbai, Maharashtra, India.

\section{Financial support and sponsorship}

Nil.

\section{Conflicts of interest}

There are no conflicts of interest.

\section{References}

1. Available from: https://who.sprinklr.com/. [Last accessed on 2020 Apr 09].

2. Chen Y, Liu Q, Guo D. Emerging coronaviruses: Genome structure, replication, and pathogenesis. J Med Virol 2020;92:418-23.

3. Lauer SA, Grantz KH, Bi Q, Jones FK, Zheng Q, Meredith HR, et al. The incubation period of coronavirus disease 2019 (COVID-19) from publicly reported confirmed cases: Estimation and application. Ann Intern Med 2020;172:577-82.

4. Wang W, Tang J, Wei F. Updated understanding of the outbreak of 2019 novel coronavirus (2019-nCoV) in Wuhan, China. J Med Virol 2020;92:441-7.

5. Guan WJ, Ni ZY, Hu Y, Liang WH, Ou CQ, He JX, et al. Clinical characteristics of coronavirus disease 2019 in China. N Engl J Med 2020;382:1708-20.

6. World Health Organization. Coronavirus Disease (COVID-19) Outbreak. Available from: https://www.who.int/emergencies/ diseases/novel-coronavirus-2019. [Last accessed on 2020 Apr 21].

7. Available from: https://www.cdc.gov/coronavirus/2019-ncov/ prevent-getting-sick/how-covid-spreads.html. [Last accessed on 2020 Apr 08].

8. Shereen MA, Khan S, Kazmi A, Bashir N, Siddique R. COVID-19 infection: Origin, transmission, and characteristics of human coronaviruses. J Adv Res 2020;24:91-8.

9. Wan Y, Shang J, Graham R, Baric RS, Li F. Receptor recognition by the novel coronavirus from Wuhan: An analysis based on decade-long structural studies of SARS coronavirus. J Virology $2020 ; 94$
10. Jaimes JA, Millet JK, Stout AE, André NM, Whittaker GR. A tale of two viruses: The distinct spike glycoproteins of feline coronaviruses. Viruses 2020;12:83.

11. Tyrrell DA, Myint SH. Coronaviruses. In: Baron S, editor. Medical Microbiology. $4^{\text {th }}$ ed.., Ch. 60. Galveston (TX): University of Texas Medical Branch at Galveston; 1996. Available from: https://www.ncbi.nlm.nih.gov/books/ NBK7782/. [Last accessed on 2020 Apr 08].

12. People Who Are at Higher Risk for Severe Illness, CDC. Available from: https://www.cdc.gov/coronavirus/2019-ncov/ need-extra-precautions/people-at-higher-risk.html. [Last accessed on 2020 Apr 08].

13. Kattan J, Kattan C, Assi T. Do checkpoint inhibitors compromise the cancer patients' immunity and increase the vulnerability to COVID-19 infection? Immunotherapy 2020;12:351-4.

14. World Health Organization. Report of the Who-China Joint Mission on Coronavirus Disease 2019 (Covid-19); 2020. Available from: https:/www.who.int/docs/default-source/ coronaviruse/who-china-joint-mission-on-covid-19-final-report. pdf. [Last accessed on 2020 Apr 08].

15. Hu Z, Song $\mathrm{C}, \mathrm{Xu} \mathrm{C}$, Jin $\mathrm{G}$, Chen $\mathrm{Y}, \mathrm{Xu} \mathrm{X}$, et al. Clinical characteristics of 24 asymptomatic infections with COVID-19 screened among close contacts in Nanjing, China. Sci China Life Sci 2020;63:706-11.

16. Velavan TP, Meyer CG. The COVID-19 epidemic. Trop Med Int Health 2020;25:278-80.

17. Zheng YY, Ma YT, Zhang JY, Xie X. COVID-19 and the cardiovascular system. Nat Rev Cardiol 2020;17:259-60.

18. Dong $\mathrm{Y}, \mathrm{Mo} \mathrm{X}, \mathrm{Hu} \mathrm{Y}$, Qi X, Jiang $\mathrm{F}$, Jiang $\mathrm{Z}$, et al. Epidemiological characteristics of 2143 pediatric patients with 2019 coronavirus disease in China. Pediatrics 2020; doi: 10.1542/peds.2020-0702.

19. Ludvigsson JF. Systematic review of COVID-19 in children shows milder cases and a better prognosis than adults. Acta Paediatrica 2020;109:1088-95.

20. Available from: https://www.cdc.gov/coronavirus/2019-nCoV/ lab/guidelines-clinical-specimens.html. [Last accessed on 2020 Apr 08].

21. Available from: https://www.cdc.gov/coronavirus/2019-nCoV/ lab/lab-biosafety-guidelines.html. [Last accessed on $2020 \mathrm{Apr}$ 08].

22. Holshue ML, DeBolt C, Lindquist S, Lofy KH, Wiesman J, Bruce H, et al. First case of 2019 novel coronavirus in the United States. N Engl J Med 2020;382:929-36.

23. Cascella M, Rajnik M, Cuomo A, Dulebohn SC, Di Napoli R. Features, Evaluation and Treatment Coronavirus (COVID-19). In: StatPearls [Internet]. Treasure Island (FL): StatPearls Publishing; 2020. Available from: https://www.ncbi.nlm.nih.gov/ books/NBK554776/. [Last updated 2020 Jul 04].

24. Simpson S, Kay FU, Abbara S, Bhalla S, Chung JH, Chung M, et al. Radiological Society of North America Expert consensus statement on reporting chest CT findings related to COVID-19. Endorsed by the Society of Thoracic Radiology, the American College of Radiology, and RSNA-Secondary Publication. J Thorac Imaging 2020;35:219-27.

25. Wong HY, Lam HY, Fong AH, Leung ST, Chin TW, Lo CS, et al. Frequency and distribution of chest radiographic findings in COVID-19 positive patients. Radiology 2019:201160.

26. American College of Radiology. ACR Recommendations for the use of Chest Radiography and Computed Tomography (CT) for Suspected COVID-19 Infection. Available from: https:// www.acr.org/Advocacy-and-Economics/ACR-PositionStatements/Recommendations-for-Chest-Radiography-and-CT- 
for-Suspected-COVID19-Infection. [Last accessed on $2020 \mathrm{Jul}$ $28]$.

27. Chung M, Bernheim A, Mei X, Zhang N, Huang M, Zeng X, et al. CT imaging features of 2019 novel coronavirus (2019nCoV). Radiology 2020;295:202-7.

28. Kong W, Agarwal PP. Chest imaging appearance of COVID-19 infection. Radiology Cardiothoracic Imaging 2020;2:e200028.

29. Bernheim A, Mei X, Huang M, Yang Y, Fayad ZA, Zhang N, et al. Chest CT findings in coronavirus disease-19 (COVID-19): Relationship to duration of infection. Radiology 2020;295:200463.

30. Pan F, Ye T, Sun P, Gui S, Liang B, Li L, et al. Time course of lung changes on chest CT during recovery from 2019 novel coronavirus (COVID-19) pneumonia. Radiology 2020. pii: 200370.

31. Bai HX, Hsieh B, Xiong Z, Halsey K, Choi JW, Tran TML, et al. Performance of radiologists in differentiating COVID-19 from viral pneumonia on chest CT. Radiology 2020:200823.

32. Salehi S, Abedi A, Balakrishnan S, Gholamrezanezhad A. Coronavirus disease 2019 (COVID-19): A systematic review of imaging findings in 919 patients. AJR Am J Roentgenol 2020;215:87-93.

33. Ng MY, Lee EY, Yang J, Yang F, Li X, Wang H, et al. Imaging profile of the COVID-19 infection: radiologic findings and literature review. Radiology 2020;2:e200034.

34. Wang Y, Dong C, Hu Y, Li C, Ren Q, Zhang X, et al. Temporal changes of CT findings in 90 patients with COVID-19 pneumonia: A longitudinal study. Radiology 2020:200843.

35. Huang L, Han R, Ai T, Yu P, Kang H, Tao Q, Xia L. Serial quantitative chest CT assessment of COVID-19: Deep-learning approach. Radiology 2020;2:e200075.

36. Song F, Shi N, Shan F, Zhang Z, Shen J, Lu H, et al. Emerging 2019 novel coronavirus (2019-nCoV) pneumonia. Radiology 2020;295:210-7.

37. Ai T, Yang Z, Hou H, Zhan C, Chen C, Lv W, et al. Correlation of chest $\mathrm{CT}$ and RT-PCR testing in coronavirus disease 2019 (COVID-19) in China: A report of 1014 cases. Radiology 2020:200642.

38. Wen Z, Chi Y, Zhang L, Liu H, Du K, Li Z, et al. Coronavirus disease 2019: Initial detection on chest $\mathrm{CT}$ in a retrospective multicenter study of 103 Chinese subjects. Radiology: Cardiothoracic Imaging 2020;2.

39. Inui S, Fujikawa A, Jitsu $\mathrm{M}$, Kunishima $\mathrm{N}$, Watanabe $\mathrm{S}$, Suzuki Y, et al. Chest CT findings in cases from the cruise ship "Diamond Princess" with coronavirus disease 2019 (COVID-19). Radiology 2020;2:e200110.

40. Fang Y, Zhang H, Xie J, Lin M, Ying L, Pang P, et al. Sensitivity of Chest CT for COVID-19: Comparison to RT-PCR. Radiology 2020:200432.

41. Rubin GD, Ryerson CJ, Haramati LB, Sverzellati N, Kanne JP, Raoof $\mathrm{S}$, et al. The role of chest imaging in patient management during the COVID-19 pandemic: A multinational consensus statement from the Fleischner society. Radiology 2020;296:17280. doi:10.1148/radiol.2020201365.

42. Hope MD, Raptis CA, Shah A, Hammer MM, Henry TS, six signatories. A role for CT in COVID-19? What data really tell us so far. Lancet 2020;395:1189-90.

43. Soldati G, Smargiassi A, Inchingolo R, Buonsenso D, Perrone T, Briganti DF, et al. Is there a role for lung ultrasound during the COVID-19 pandemic? J Ultrasound Med 2020;39:1459-62.

44. Chaari A, Bousselmi K, Assar W, Kumar V, Khalil E, Kauts V, et al. Usefulness of ultrasound in the management of acute respiratory distress syndrome. Int J Crit Illn Inj Sci 2019;9:11-5.

45. Poggiali E, Dacrema A, Bastoni D, Tinelli V, Demichele E,
Mateo Ramos P, et al. Can lung US help critical care clinicians in the early diagnosis of novel coronavirus (COVID-19) pneumonia? Radiology 2020;295:E6.

46. Peng QY, Wang XT, Zhang LN; Chinese Critical Care Ultrasound Study Group. Findings of lung ultrasonography of novel coronavirus pneumonia during the 2019-2020 epidemic. Intensive Care Med 2020;46:849-50.

47. Huang Y, Wang S, Liu Y, Zhang Y, Zheng C, Zheng Y, et al. A preliminary study on the ultrasonic manifestations of peripulmonary lesions of non-critical novel coronavirus pneumonia (COVID-19). SSRN Electronic J 2020. doi:10.2139/ ssrn. 3544750 .

48. Soldati G, Smargiassi A, Inchingolo R, Buonsenso D, Perrone T, Briganti DF, et al. Proposal for international standardization of the use of lung ultrasound for patients with COVID-19. J Ultrasound Med 2020;39:1413-9.

49. World Health Organization. Clinical Management of Severe Acute Respiratory Infection When Novel Coronavirus (? 2019-nCoV)" Infection is Suspected: Interim Guidance, 28 January 2020. World Health Organization; 2020. [Last accessed on 2020 Apr 08].

50. CDC. Available from: https://www.cdc.gov/coronavirus/2019ncov/hcp/clinical-guidance- management-patients.html. [Last accessed on 2020 Apr 08].

51. FDA. Available from: https://www.fda.gov/emergencypreparedness-and-response/mcm- issues/coronavirus-disease2019-covid-19. [Last accessed on 2020 Apr 08].

52. Available from: https:/www.who.int/emergencies/diseases/novelcoronavirus-2019/technical-guidance/infection-prevention-andcontrol. [Last accessed on $2020 \mathrm{Apr}$ 08].

53. Available from: https://icmr.nic.in/content/covid-19. [Last accessed on 2020 Apr 08].

54. Gao J, Tian Z, Yang X. Breakthrough: Chloroquine phosphate has shown apparent efficacy in treatment of COVID-19 associated pneumonia in clinical studies. Biosci Trends 2020;14:72-3.

55. Wang $\mathrm{M}$, Cao $\mathrm{R}$, Zhang $\mathrm{L}$, Yang $\mathrm{X}$, Liu J, Xu M, et al. Remdesivir and chloroquine effectively inhibit the recently emerged novel coronavirus $(2019-\mathrm{nCoV})$ in vitro. Cell Res 2020;30:269-71.

56. Yao X, Ye F, Zhang M, Cui C, Huang B, Niu $\mathrm{P}$, et al. In vitro antiviral activity and projection of optimized dosing design of hydroxychloroquine for the treatment of severe acute respiratory syndrome coronavirus 2 (SARS-CoV-2). Clin Infect Dis 2020. doi:10.1093/cid/ciaa237.

57. Colson P, Rolain JM, Lagier JC, Brouqui P, Raoult D. Chloroquine and hydroxychloroquine as available weapons to fight COVID-19. Int J Antimicrob Agents 2020;55:105932.

58. World Health Organization. Coronavirus: Landscape Analysis of Therapeutics as of 17 February, 2020. Available from: https:// www.who.int/blueprint/priority-diseases/key-action/Table_of_ therapeutics_Appendix_17022020.pdf?ua=1. [Last accessed on 2020 Apr 08].

59. Cortegiani A, Ingoglia G, Ippolito M, Giarratano A, Einav S. A systematic review on the efficacy and safety of chloroquine for the treatment of COVID-19. J Crit Care 2020;57:279-83.

60. ESICM, SCCM. Surviving Sepsis Campaign Rapid Guidelines of the Management of Critically ill Adults with Coronavirus Disease 2019 (pre-publication). Available from: https://www. esicm.org/ssc-covid19-guidelines/. [Last accessed on $2020 \mathrm{Apr}$ 08].

61. Beigel JH, Tomashek KM, Dodd LE, Mehta AK, Zingman BS, Kalil AC, et al. Remdesivir for the treatment of Covid-19 - Preliminary report. N Engl J Med 2020 May 22. 
62. Chan KW, Wong VT, Tang SC. COVID-19: An update on the epidemiological, clinical, preventive and therapeutic evidence and guidelines of integrative Chinese-Western medicine for the management of 2019 novel coronavirus disease. Am J Chin Med 2020;48:737-62.

63. US Food and Drug Administration. Investigational New Drug (IND) or Device Exemption (IDE) Process (CBER). US Food and Drug Administration. Available from: https://www. fda.gov/biologicsbloodvaccines/developmentapprovalprocess/ investigationalnewdrugindordeviceexemptionideprocess/default. htm. [Last accessed on 2020 Apr 08].

64. World Health Organization. Clinical Management of Severe Acute Respiratory Infection When Novel Coronavirus (nCoV) Infection is Suspected. Available from: https://www.who. int/publications-detail/clinical-management-of-severe-acuterespiratory-infection-when-novel-coronavirus-(ncov)-infection-issuspected. [Last accessed on 2020 Apr 08].

65. Jin YH, Cai L, Cheng ZS, Cheng H, Deng T, Fan YP, et al. A rapid advice guideline for the diagnosis and treatment of 2019 novel coronavirus (2019-nCoV) infected pneumonia (standard version). Military Med Res 2020;7:4.

66. Fang L, Karakiulakis G, Roth M. Are patients with hypertension and diabetes mellitus at increased risk for COVID-19 infection?. Lancet Respir Med 2020;8. doi:10.1016/s2213-2600(20)30116-8.

67. Gautret P, Lagier JC, Parola P, Meddeb L, Mailhe M, Doudier B, et al. Hydroxychloroquine and azithromycin as a treatment of COVID-19: Results of an open-label non-randomized clinical trial. Int J Antimicrobial Agents 2020. pii: 105949.

68. Bajpai J, Tsang J. Novel coronavirus infection - Knowns and unknowns with particular reference to oncology - Combating against COVID-19 with "COVID." Indian Journal of Medical and Paediatric Oncology 2020;41:116.

69. The American Cancer Society Cancer Action Network: COVID-19 Pandemic Impact on Cancer Patients and Survivors Survey Findings Summary; 2020. Available from: https://www. kff.org/other/state-indicator/total-population/. [Last accessed on 2020 Apr 19].

70. American Society of Clinical Oncology: COVID-19 Patient Care Information | ASCO; 2020. Available from: https://www.asco. org/asco-coronavirus-information/care-individuals-cancer-duringcovid-19. [Last accessed on 2020 Apr 19].

71. COVID-19 Provider \& Practice Information, ASCO. Available from: https://www.asco.org/asco-coronavirus-information/ provider-practice-preparedness-covid-19. [Last accessed on 2020 Apr 09].

72. Mailankody S, Bajpai J. Intelligent adaptation to the changing surroundings amidst the COVID-19 pandemic for sarcomas and melanomas. Cancer Res Stat Treatment 2020;3:110.

73. Sequence for Donning Personal Protective Equipment. Available from: https://www.cdc.gov/HAI/pdfs/ppe/ppeposter1322.pdf. [Last accessed on 2020 Apr 08].

74. COVID-19: Lockdown Across India, in line with WHO Guidance. UN News; 24 March 2020. [Last accessed on 2020 Apr 08]. 